\title{
AN EXPERIMENTAL STUDY OF TIP CLEARANCE FLOW IN A RADIAL INFLOW TURBINE
}

\author{
R. Dambach and H.P. Hodson \\ Whittle Laboratory \\ University of Cambridge \\ Cambridge, United Kingdom
}

\author{
I. Huntsman \\ Dept. of Mech. Engineering \\ University of Canterbury \\ Christchurch, New Zealand
}

\begin{abstract}
This paper describes an experimental investigation of tip clearance flow in a radial inflow turbine. Flow visualisation and static pressure measurements were performed. These were combined with hot-wire traverses into the tip gap. The experimental data indicates that the tip clearance flow in a radial turbine can be divided into three regions. The first region is located at the rotor inlet, where the influence of relative casing motion dominates the flow over the tip. The second region is located towards midchord, where the effect of relative casing motion is weakened. Finally a third region exists in the exducer, where the effect of relative casing motion becomes small and the leakage flow resembles the tip flow behaviour in an axial turbine.

Integration of the velocity profiles showed that there is little tip leakage in the first part of the rotor because of the effect of scraping. It was found that the bulk of tip leakage flow in a radial turbine passes through the exducer. The mass flow rate, measured at four chordwise positions, was compared with a standard axial turbine tip leakage model. The result revealed the need for a model suited to radial turbines. The hot-wire measurements also indicated a higher tip gap loss in the exducer of the radial turbine. This explains why the stage efficiency of a radial inflow turbine is more affected by increasing the radial clearance than by increasing the axial clearance.
\end{abstract}

$\begin{array}{ll}\text { NOMENCLATURE } & \\ \Delta \mathrm{h}_{0} & \text { isentropic stagnation enthalpy change } \\ \dot{\mathrm{m}} & \text { mass flow rate } \\ \mathrm{p} & \text { static pressure } \\ \mathrm{p}_{0} & \text { stagnation pressure } \\ \mathrm{p}^{*}=\mathrm{p}-{ }^{*} /{ }_{2} \rho \mathrm{U}^{2} & \text { reduced static pressure } \\ \mathrm{v} & \text { velocity } \\ \mathrm{w} & \text { blade thickness (y-axis) } \\ \mathrm{t}, \tau & \text { tip gap height (z-axis) } \\ \mathrm{C}_{\mathrm{p}}^{*} & \text { reduced static pressure coefficient } \\ \mathrm{R}^{*} & \text { scraping ratio } \\ \mathrm{S} & \text { blade length } \\ \mathrm{S}_{\mathrm{m}} & \text { meridional length }\end{array}$

blade speed

loss coefficient relative flow angle local blade angle (camber line) flow angle relative to the blade density
Subscripts
3
$\mathrm{n}$
$\mathrm{p}$

\author{
stator inlet \\ rotor inlet \\ blade normal \\ rotor blade passage
}

\section{INTRODUCTION}

The behaviour of tip clearance flow in axial turbines has been investigated in detail. A number of tip gap mass flow models and tip clearance loss models for axial turbines have been developed as a result of the better understanding of the tip gap flow. The most important omission for these models, with the exception of Rains (1954) and Yaras and Sjolander (1992a), is the effect of relative wall motion. According to Yaras and Sjolander (1992b) and in the light of the present investigation more data is needed to clarify the effect of relative casing motion on tip clearance flow.

Very little is known about tip clearance flow in radial turbines. This is partly because a radial turbine blade row cannot be investigated in a linear cascade environment and detailed measurements in small radial machines are very difficult. The best known investigation of clearance effects on the overall performance of a radial turbine was undertaken by Futral and Holeski (1970). Tests investigated clearance effects at the rotor inlet and exit. They concluded that radial clearance increases at the rotor exit have about 10 times the effect on the overall efficiency as axial clearance increases at the rotor inlet. Reasons for this have never been put forward.

During the present investigation it has become apparent, that the relative casing motion cannot be neglected in the study of tip 
clearance flow in radial turbines. The objectives of this paper are to understand the flow structure over the tip of a radial inflow turbine, to quantify the mass flow rate over the tip and to establish a qualitative estimate of tip gap loss in a radial turbine. The results will then be used to explain why the overall performance of a radial inflow turbine suffers less from an increase in axial clearance than from the same increase in radial clearance as a percentage of local span.

\section{EXPERIMENTAL APPARATUS}

The radial inflow turbine has been described by Huntsman et al (1991, 1993 and 1994) in detail. The working section is shown schematically in Figure 1.

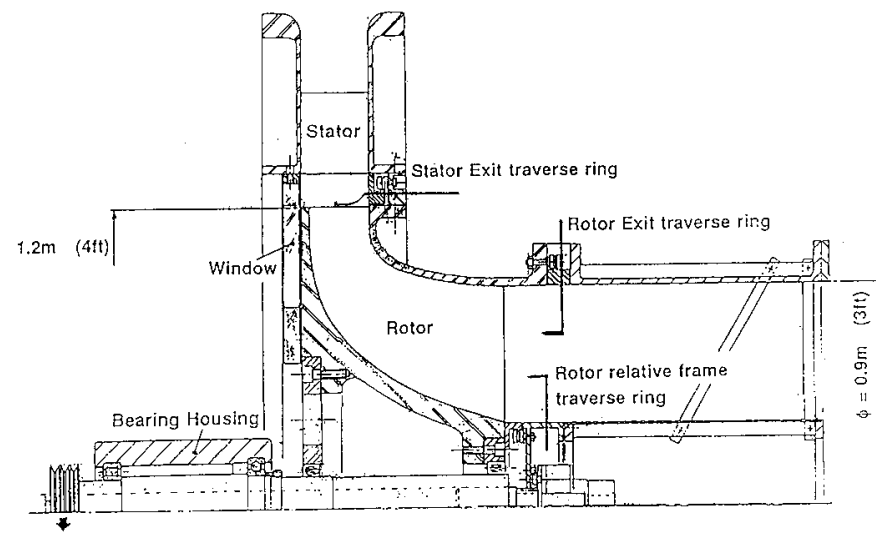

Figure 1: Schematic of the radial inflow turbine test facility

All measurements were performed at the design condition as described by Huntsman (1993). Table 1 summarises the most important parameters for this particular study in the tip gap region.

\begin{tabular}{|l|l|}
\hline Rotational speed & $450 \mathrm{rpm}$ \\
\hline Mass flow rate & $4.5 \mathrm{~kg} / \mathrm{s}$ \\
\hline No. of rotor blades & 14 \\
\hline Average blade normal thickness at the tip & $8 \mathrm{~mm}$ \\
\hline Axial clearance at rotor inlet & $1.2 \mathrm{~mm}$ \\
\hline Radial clearance at rotor exit & $1.8 \mathrm{~mm}$ \\
\hline Meridional chord at the casing & $460 \mathrm{~mm}$ \\
\hline Rotor inlet radius & $609 \mathrm{~mm}$ \\
\hline Rotor exit radius at the tip & $445 \mathrm{~mm}$ \\
\hline Rotor inlet angle (mean flow) & $-18.4^{\circ}$ \\
\hline Rotor exit angle at the tip (mean flow) & $-72^{\circ}$ \\
\hline Pressure side tip corner radius & $0.25 \mathrm{~mm}$ \\
\hline
\end{tabular}

Table 1: Leading parameters for the test section at the design point

The tip gap height of the present radial inflow turbine can be approximated by a third order polynomial. The inlet and exit clearance and clearances of $1 \mathrm{~mm}$ at $\mathrm{S}_{\mathrm{m}}=21 \%$ and $1.35 \mathrm{~mm}$ at $\mathrm{S}_{\mathrm{m}}=63 \%$ are needed to describe the polynomial. The tip gap height corresponds to about 0.6 percent of the local blade height.

\section{EXPERIMENTAL TECHNIQUES}

\section{Flow Visualisation in the Tip Gap Region}

The flow features of the rotor tip region were visualised by using Ammonia gas and "Ozalid" paper. This technique was previously used by Huntsman et al. (1991) in the same rig. The diazo paper was stuck onto the flat surface of the blade tip, using double-sided adhesive tape. The angle of the flow trace was read with a vernier protractor $(+/-1$ degree). Two different flow visualisation experiments were conducted.

1. The ammonia gas was ejected through a vinyl tube (outer diameter $1.27 \mathrm{~mm}$ ). The end of the vinyl tube was set flush with the blade tip surface in the pressure side corner of the tip gap. Nineteen flow traces between 5\% and 96\% meridional length were obtained.

2. The end of the vinyl tube was set flush with the blade tip surface in the suction side corner of the tip gap. Seven flow traces between $2.5 \%$ and $38 \%$ meridional length were obtained.

\section{Static Pressure Measurements on the blade tip surface}

A high resolution measurement technique (Bindon, 1987) was used to measure the pressure on the blade surface in the gap region. As shown in Figure 2, a $16 \mathrm{~mm}$ deep and $2 \mathrm{~mm}$ wide slot was cut across the blade tip along a constant $\mathrm{r} \theta$-line. The slot, located at $\mathrm{S}_{\mathrm{m}}=$ $46.6 \%$, was sealed with adhesive tape. With a needle the tape could be punctured at any point, allowing 9 measurement points over the width of the blade tip. The pneumatic data was measured using a Scanivalve pressure switch fitted to the centre line of the rotor. The effect of the centripetal acceleration on the air in the pressure lines was accounted for in the data reduction.

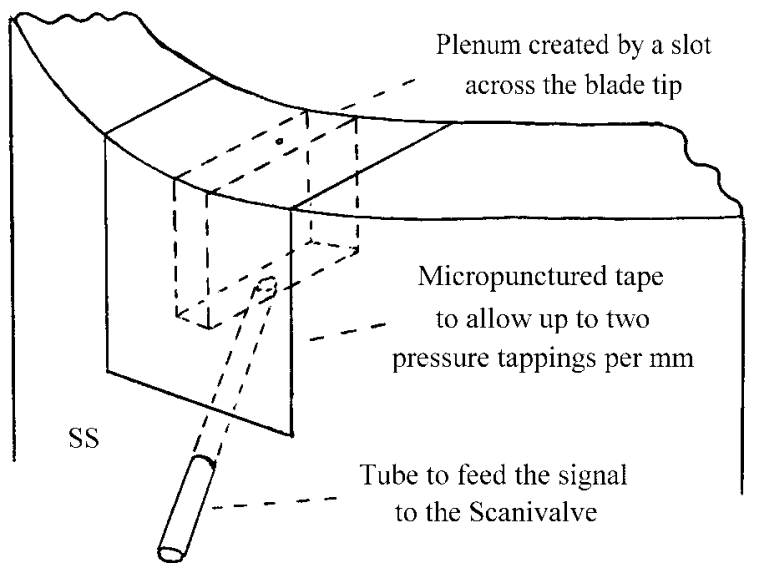

Figure 2: High resolution pressure measurement technique

\section{Static Pressure Measurements at the rotor casing}

The static pressure at the casing was measured at 21 locations between $9.2 \%$ and $100 \%$ of meridional blade length. The pressure tappings were located at a constant $r \theta$-value. The logging of the static pressure data was triggered by a once per revolution trigger pulse. The time-mean, steady state pressure level was obtained using a Scanivalve pressure switch. The unsteady pressure variation was measured with a Kulite XCS062 pressure transducer (frequency response of $125 \mathrm{kHz}$ ) in the same tappings. Between 18 and 23 measurements were taken over the width of the blade. The fluctuating 
pressure (AC coupled) was subsequently added to the steady pressure for each pressure tapping and ensembled averaged over 50 passages.

\section{Hot-wire Traverses into the Tip Gap}

A single axis hot-wire was employed in the gap region to examine the flow field between the blade tip and the casing. The hotwire was mounted upon a two-axis traverse gear, which allowed the sensor to turn around its own axis and to move into the gap in the spanwise direction. Because the measurements are taken in the absolute frame, the advantage of this method is that reverse flow regions in the relative frame can be measured. The high spatial and temporal resolution of a hot-wire anemometer and the negligible blockage of the probe make the instrument a very appropriate means of acquiring experimental data in such an environment (see also Pandya and Lakshminarayana, 1983).

The hot-wire was calibrated for angle and velocity sensitivity in a $1.2 \mathrm{~mm}$ slot with a rounded inlet of radius $5 \mathrm{~mm}$. This procedure simulated roughly the tip gap environment in the radial inflow turbine. The hot-wire traverse in the radial turbine consisted of 33 positions over the distance from the casing to within $0.25 \mathrm{~mm}$ of the blade tip. At each immersion the hot-wire was rotated around its axis to 6 different angular positions, covering a range from $\alpha=90^{\circ}$ (hot-wire perpendicular to the meridional vector) to $\alpha=-60^{\circ}$ (see Figure 3).

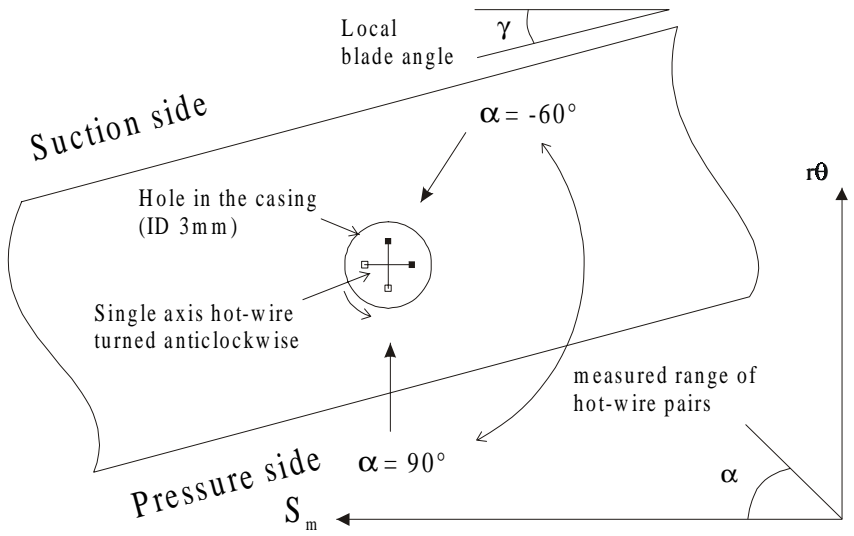

Figure 3: Hot-wire set-up in the tip gap of the radial turbine

A measurement was triggered once per revolution and each trace was ensembled averaged. The signal was then processed in order to deduce the flow angle and velocity magnitude. The 6 sensor positions formed 3 different pairs. In order to deduce the absolute flow angle the two hot-wire pairs were chosen with most equal velocity readings and the angle was calculated with a linear blending function. The velocity magnitude was deduced from the hot-wire position most perpendicular to the absolute flow angle, once the flow angle was known. Errors due to calibration and signal randomness introduce an uncertainty, especially when transforming the measured absolute velocities into the relative frame. At $\mathrm{S}_{\mathrm{m}}=21 \%$, where the absolute tip flow angle was close to 90 degrees, the maximum error on the relative velocity inside the gap was $+/-4 \%$ of the local tip speed and the maximum error on the relative angle was $+/-10$ degrees. For all other measurement locations the error on the relative velocity was less than $+/-3 \%$ of the local tip speed and the error on relative angle was less than $+/-4$ degrees.

\section{RESULTS AND DISCUSSION}

The first aim of this project was to visualise the flow over the rotor tip of the radial inflow turbine. This is presented below. The local tip flow features are then examined closely at one particular chordwise position before expanding the discussion to the whole chord.

\section{The tip flow visualised}

Ammonia traces over the tip of the rotor blade are shown in Figure 4. The estimated flow angle, obtained from the flow visualisation at the blade tip surface, is shown in Figure 5. Three different tip flow regimes are identifiable.

1. Over the first $20 \% \mathrm{~S}_{\mathrm{m}}$ the flow trace indicates that the tip flow is strongly inclined in the streamwise direction. The result of a more detailed study, where ammonia gas was fed into the gap from the suction side, showed that tip flow moves partly from the suction side to the pressure side in this region. The relative casing motion causes fluid to recirculate over the tip for high radii and low local blade angle. This recirculation zone in the inducer is responsible for the indistinct trace when feeding Ammonia gas into the gap from the pressure side. Recently Amedick and Simon (1997) calculated the flow through a radial inflow turbine with tip clearance. For their turbine they discovered that for the first $6 \%$ of $\mathrm{S}_{\mathrm{m}}$ the tip gap flow is dominated by the relative casing motion.

2. Between $20 \%$ and $60 \%$ of $S_{m}$ the flow direction is found to be almost perpendicular to the blade. The sharp flow trace near the blade tip surface in Figure 4 indicates that the tip flow is driven mainly by the pressure difference over the tip.

3. Downstream of $60 \% \mathrm{~S}_{\mathrm{m}}$ the streamlines over the tip are inclined in the streamwise direction and diverge more strongly towards the trailing edge than in the previous region. The changes in blade loading near the tip are responsible for the alteration of the flow patterns. As Huntsman (1993) showed the blade was designed so that the reduced static pressure, $\mathrm{p}^{*}$, on the pressure surface at the design flow condition is uniform for the first $50 \%$ of the blade length (i.e. $\mathrm{S}_{\mathrm{m}}$ $=60 \%$ ) and then falls rapidly towards the rear of the blade, because the main flow is accelerated. Hence the component of velocity parallel to the local blade angle increases. Since this component is carried into the tip gap largely unchanged (Rains, 1954), the tip flow becomes less perpendicular to the blade chord. This effect is enhanced, because the pressure difference across the blade tip is also decreasing so that the velocity normal to the blade chord is reduced. The same phenomenon was found by Heyes and Hodson (1993) in an axial blade row.

\section{The nature of tip leakage flow at midchord}

The most detailed tip investigation has been performed at $46 \% \mathrm{~S}$. Figure 6 shows the relative velocity vectors in the vicinity of the tip that were measured with the hot-wire anemometer. As the flow is driven into the gap by the pressure difference over the blade, it is turned toward the blade normal direction. The turning of the tip leakage flow is completed at a fraction of blade thickness $(y / w)$ of 0.75. The relative angle for a given radial immersion and the streamwise momentum were found to be constant between $y / w=-0.1$ and $y / w=0.75$. Outside this region, where steep velocity gradients occurred, a maximum error of $8 \%$ of the blade speed was estimated due to spatial averaging. 


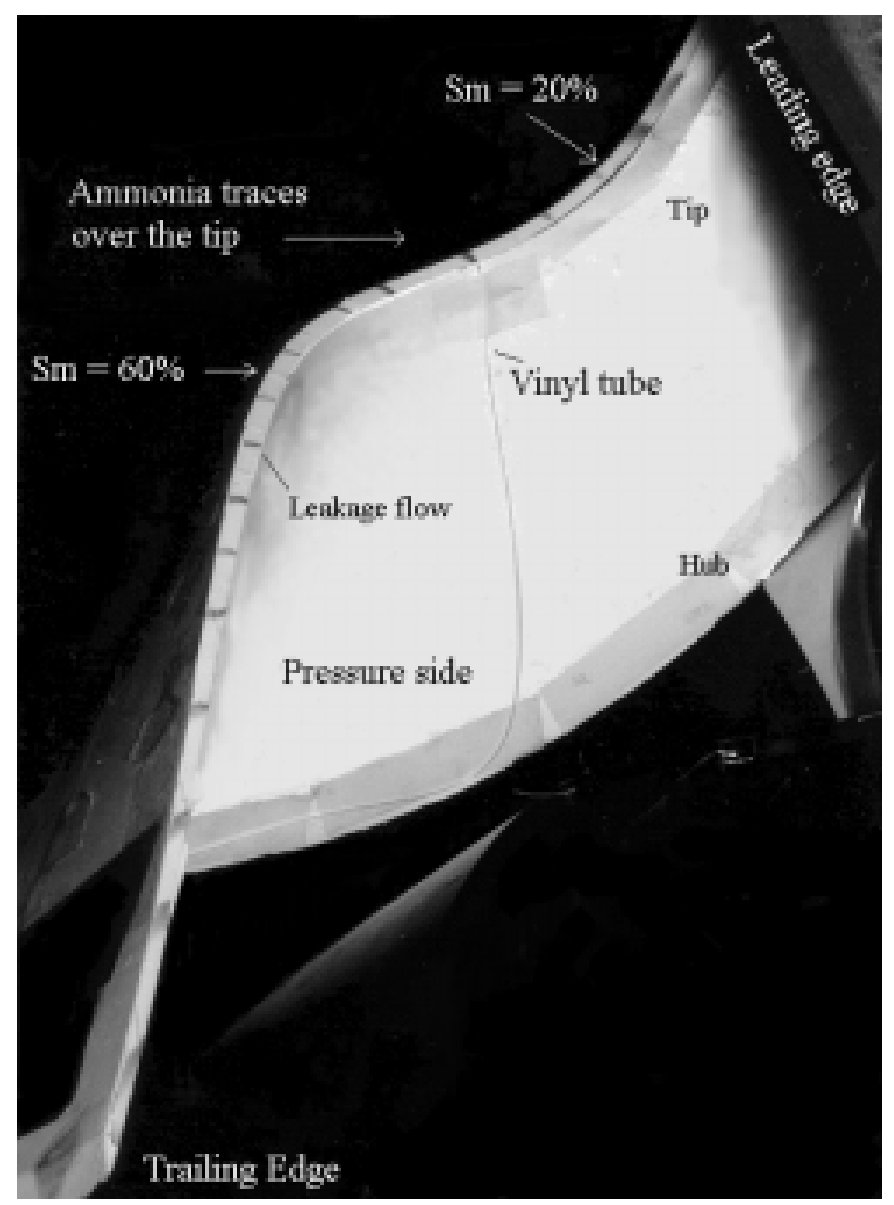

Figure 4: Flow visualisation in the tip region

The thin shear layer close to the casing could not be fully resolved for this tip gap configuration. Nevertheless Figure 6 indicates a variation in the relative angle over the height of the gap, which is caused by viscous forces near the casing. Near the gap exit (i.e. on the suction side) the flow angle relative to the blade varies from $\delta=-21^{\circ}$ near the casing to $\delta=69^{\circ}$ at a fraction of gap height (z/t) of 0.75 ( $\delta$ is positive in the direction of rotation). Given the skew of relative angle inside the gap, this latter angle agrees well with the value of $\delta=76^{\circ}$ determined from detailed flow visualisation experiments at the blade surface (see Figure 5). The skew in relative angle has also been found by Sjolander and Cao (1995) in axial turbines.

Once the tip flow has left the tip gap at the suction side, it is opposed by flow adjacent to the casing, which is moving towards the gap exit on the suction side due to a no-slip condition at the casing. This flow (subsequently called "scraping" flow) turns the tip leakage jet sharply into the main flow direction (see Figure 6) or towards the hub (as observed in flow visualisation not presented here) and the two opposing fluids create a lift off line. This lift off line is associated with the formation of the scraping vortex, described by Huntsman and Hodson (1994) and Amedick and Simon (1997).

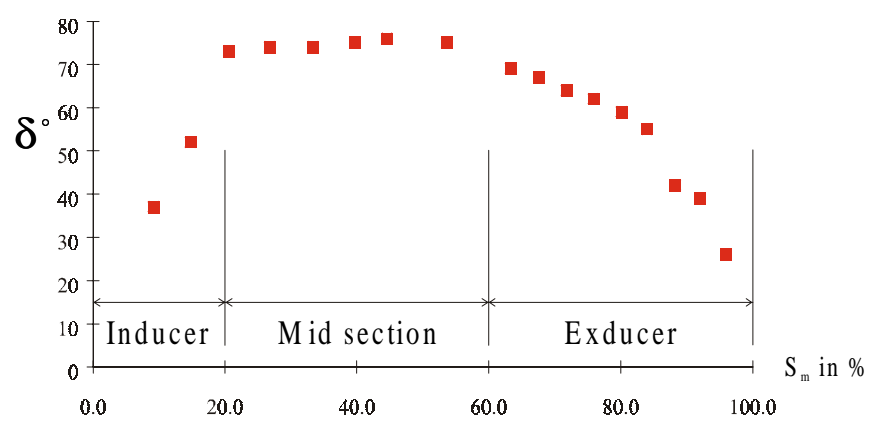

Figure 5: Flow angle at the blade surface determined from the flow visualisation experiment

Figure 7 shows the tangential velocity components for the same location as Figure 6. It is observed in Figure 7 that the tip leakage flow undergoes two accelerations. The first occurs at tip gap entry and is well documented by previous research in axial turbines (e.g. Bindon, 1987). The new feature observed in the present work is a second but weaker acceleration of the tip leakage flow towards the gap exit. This acceleration is linked with the fact that the tip leakage flow at gap exit is opposed by the scraping flow. This has two effects.

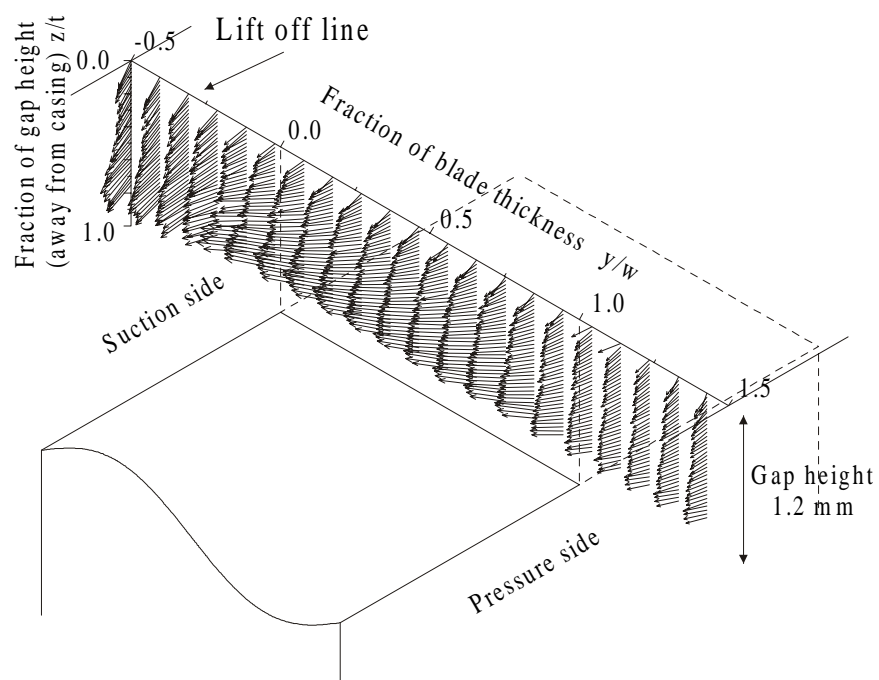

Figure 6: Relative velocity vectors at $\mathrm{S}_{\mathrm{m}}=46 \%$

1. A small part of the scraping fluid moves into the gap from the suction side and is dragged through the entire tip gap. The consequence is an area reduction for the tip gap flow and a substantial reduction of tip leakage flow in parts of the radial turbine.

2. The part of scraping fluid, which is not transported into the gap, is blocked by the leakage jet at the gap exit and "scraped" off the blade. The scraped fluid and the tip leakage jet form a dividing stream surface at $-0.25 \mathrm{y} / \mathrm{w}$ which is indicated by a line of zero blade normal velocity in the blade normal view of Figure 7. As a result of this dividing stream surface a static pressure rise is expected. 


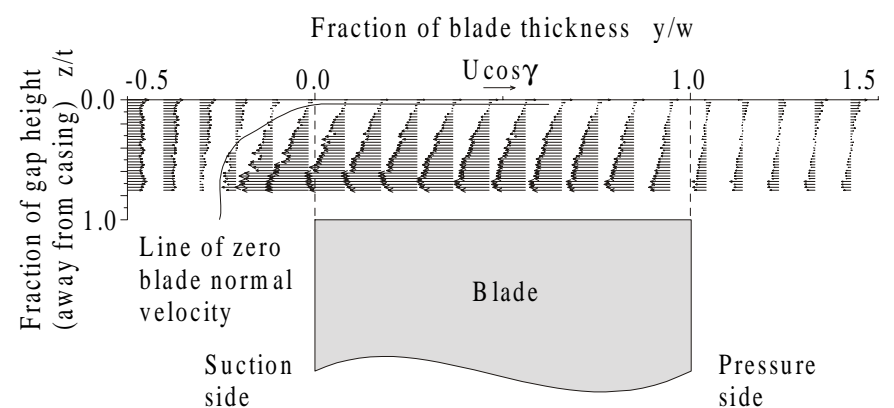

Figure 7: Blade normal velocity vectors at $\mathrm{S}_{\mathrm{m}}=46 \%$

Static pressure measurements in the tip region confirm the observations made by the hot-wire measurements. All static pressure data is non-dimensionalised by the blade dynamic head at rotor inlet and is presented in the form of the reduced pressure coefficient

$$
C p_{\text {staic }}^{*}=\frac{p-p_{03 r e l}-1 / 2 \rho\left(U^{2}-U_{3}^{2}\right)}{1 / 2 \rho U_{3}^{2}}
$$

The relative stagnation pressure at rotor inlet, $\mathrm{p}_{\text {0зас }}$, was calculated from the measured inlet stagnation pressure, $\mathrm{p}_{01}$, and the mass averaged loss of stagnation pressure at the exit from the stator blades $\left(\mathrm{Y}_{\text {sutor }}=\right.$ 0.021). Using the rotational form of Bernoulli's equation (1) becomes

$$
C p_{\text {satic }}^{*}=\frac{p^{*}-\left(p_{03}-\rho U_{3} V_{\Theta 3}\right)}{1 / 2 \rho U_{3}^{2}}
$$

Figure 8 presents the static pressure data obtained at $46 \% \mathrm{~S}_{\mathrm{m}}$. The pressure coefficient at the blade tip shows that the first acceleration into the gap is completed at $\mathrm{y} / \mathrm{w}=0.85$ (i.e. one gap height from the pressure side corner). After the vena contracta the pressure recovers due to mixing inside the gap. The effect of this acceleration on the pressure at the casing occurs further into the gap and is smaller in magnitude because of streamline curvature. The pressure minimum at the casing is located at $y / w=0.7$. The same behaviour has been reported by Bindon (1987) in an axial turbine cascade. The different level of pressure recovery between casing and blade surface may be due to streamline curvature of the opposite sense after the vena contracta. The effect of spatial averaging of the Kulite probe was calculated to be of no more than $0.025 \mathrm{C}_{\mathrm{p}}^{*}$.

Heyes and Hodson (1993) suggest that complete mixing inside the gap of an axial turbine occurs for a gap width larger than six times the gap height $(\tau / \mathrm{w}=1 / 6)$. A contraction coefficient of 0.81 is calculated from the pressure at the blade surface if complete mixing occurs in the gap of the present radial turbine $\left(\tau / \mathrm{w}=0.15\right.$ at $\left.46 \% \mathrm{~S}_{\mathrm{m}}\right)$. This is equivalent to a discharge coefficient of 0.97 and is in accordance with the predicted discharge coefficient $\left(C_{D}=0.96\right)$ for the given pressure side corner radius (Heyes and Hodson, 1993). In this context it is important to note that pressure side corner radii in real life turbines are often larger than those used in tip clearance research. A discharge coefficient close to one is very likely in such environments. Hence it is questionable whether a tip gap mass flow model for radial turbines should be based on discharge coefficients.

The second pressure drop after the vena contracta corresponds to the second acceleration near the gap exit, discovered in Figure 7. Flow visualisation showed that there is little streamline divergence in the blade to blade plane over the tip at $S_{\mathrm{m}}=46 \%$. An incompressible Bernoulli calculation can be applied to a blade normal section of the tip gap flow field as displayed in Figure 7. The increase in maximum velocity that represents the acceleration after the vena contracta $(0.0<$ $\mathrm{y} / \mathrm{w}<0.3$ ) corresponds to a $\Delta \mathrm{C}_{\mathrm{p}}^{*}$ of 0.35 . Hence the simple Bernoulli calculation confirms that the second pressure drop in Figure $8(\mathrm{y} / \mathrm{w}<$ 0.3 ) is an inviscid phenomena. As observed previously the acceleration is due to a mean reduction in tip leakage flow area.

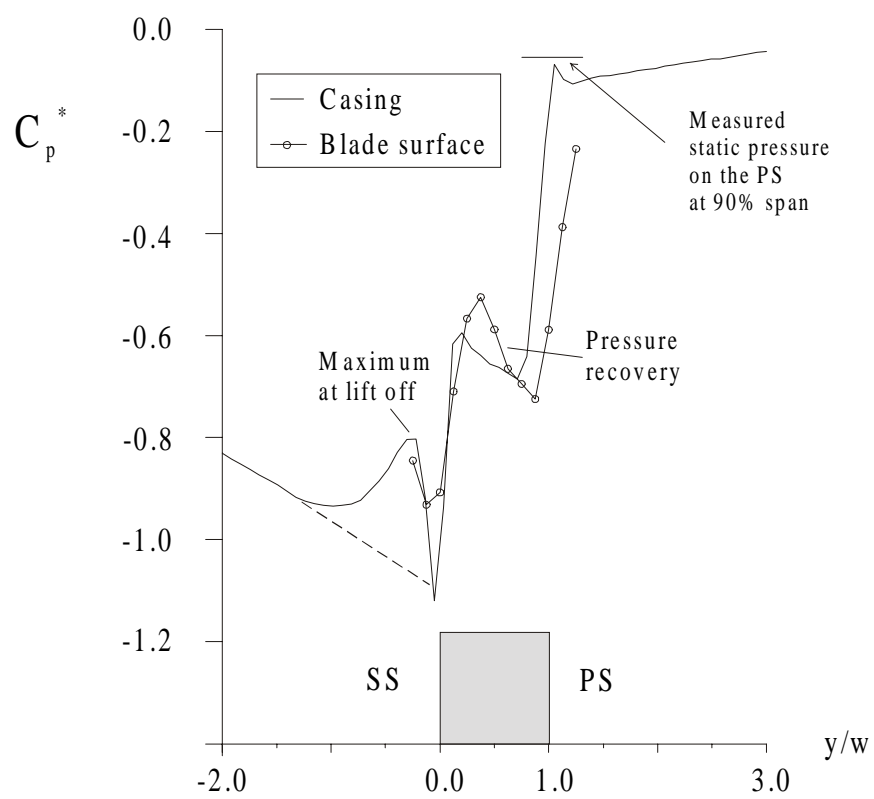

Figure 8: Static pressure in the tip region at $\mathrm{S}_{\mathrm{m}}=46 \%$

In Figure 8, a local pressure maximum can be observed near the suction side at $\mathrm{y} / \mathrm{w}=-0.25$. The local maximum confirms the expected rise in static pressure due to the dividing stream surface observed in Figure 7. The extrapolation (dashed line) also suggests that this local pressure maximum does not influence the driving pressure difference for the tip leakage flow.

The pressure driven tip clearance flow at $46 \% \mathrm{~S}_{\mathrm{m}}$ interacts strongly with the scraping fluid near the casing. The dragged fluid reduces the flow area in the tip gap and its opposition to the leakage jet is responsible for a second acceleration near the tip gap exit. It will be seen in the following paragraph that the behaviour of gap flow in the mid-section is in a transition regime between the behaviour of leakage flow in the inducer and the exducer.

\section{Tip clearance flow over the whole chord}

Figure 9 shows the loading distribution for different spanwise positions. The pressure at $90 \%$ span was obtained from data measured by Huntsman (1993). The pressure at the casing was obtained from 20 different static pressure traces, one of which is shown in Figure 8. The minimum pressure was taken from the ensembled data and was averaged over 5 blade passages. 


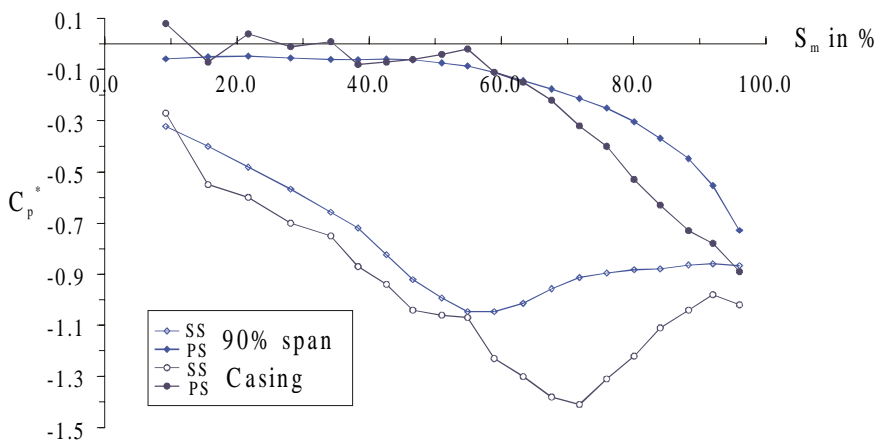

Figure 9: Loading distribution for different spanwise positions

If there was zero tip clearance, then the scraping fluid would stagnate on the blade suction surface and travel off at right angles as scraped fluid. By solving the Bernoulli equation Rains (1954) computed the pressure difference between far upstream and the suction side corner with zero clearance. This "scraping" dynamic head amounts to ${ }^{1} / 2 \rho U^{2} \cos ^{2} \gamma$, where $\gamma$ is the angle between the camber line at the tip and the meridional direction (see Figure 3). With a clearance larger than zero, the driving pressure difference over the tip $\left(\Delta \mathrm{p}_{\text {tipnow }}\right)$ is opposed by the scraping dynamic head. In order to quantify the effect of scraping on the tip clearance flow, the authors prefer however to think in terms of momentum. A "scraping" ratio R can be defined as the undisturbed tip gap flow momentum divided by the scraping momentum (see Figure 10). Since the streamwise momentum over the tip is largely conserved, the driving pressure difference $\left(\Delta \mathrm{p}_{\text {tiplow }}\right)$ was calculated between $p^{*}$ at $90 \%$ span on the pressure side and p* at the casing near the suction side gap exit (Rains, 1954).

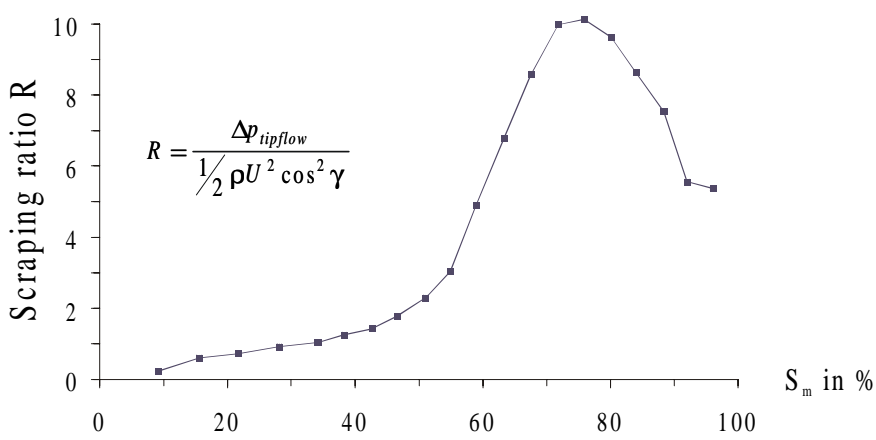

Figure 10 A relative measure of the effect of scraping

The strength of this scraping ratio $\mathrm{R}$ is believed to be responsible for the amount of scraping fluid dragged through the gap. A scraping ratio less than one between the leading edge and $30 \% \mathrm{~S}_{\mathrm{m}}$ indicates a strong effect of scraping in the inducer of the present radial turbine and much dragged fluid is to be expected in this region. A scraping ratio much larger than one between $60 \% \mathrm{~S}_{\mathrm{m}}$ and the trailing edge indicates a small effect of scraping in the exducer.

Figure 11 displays blade normal velocity vectors over the tip gap for a position near the inducer and in the exducer. At $S_{m}=21 \%$ dragged fluid occupies the upper half of the gap height. The large amount of dragged fluid in the gap is believed to be a result of a scraping ratio smaller than one $(\mathrm{R}=0.73)$. The tip leakage flow in the inducer seems to be clearly dominated by the scraping effect.
At $\mathrm{S}=63 \%$ and $\mathrm{S}=88 \%$ (not presented here) the effect of scraping is so much reduced that it could not be measured by the hotwire traverse anymore. The small quantity of dragged fluid in the gap near the exducer is a consequence of the high scraping ratio observed in Figure 10. This suggests that the tip leakage flow in the exducer of a radial turbine resembles the tip flow behaviour in axial turbines, where the tip gap flow is dominated by pressure differences rather than by the scraping effect (Yaras and Sjolander, 1992a).

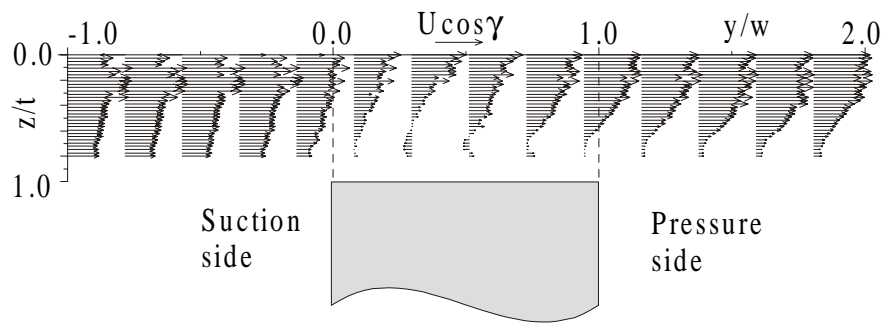

a) Blade normal velocity vectors at $S_{m}=21 \%$

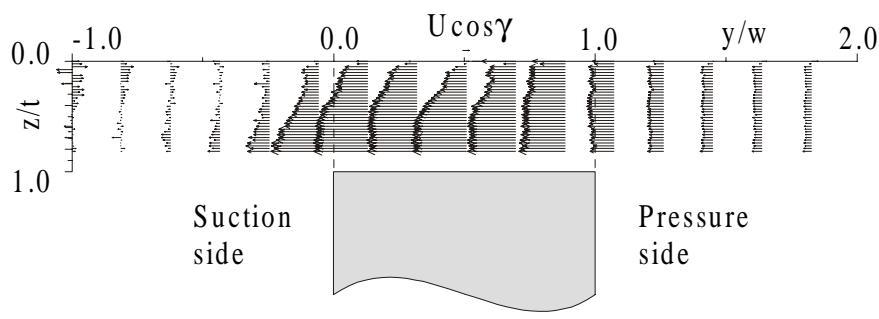

b) Blade normal velocity vectors at $\mathrm{S}_{\mathrm{m}}=63 \%$

Figure 11: Velocity vectors near inducer and exducer

Figure 12 shows the reduced static pressure coefficient at the casing for the same two chordwise positions. The pressure at $21 \% \mathrm{~S}_{\mathrm{m}}$ is approximately constant inside the gap and drops only on the suction side between $\mathrm{y} / \mathrm{w}=0.0$ and $\mathrm{y} / \mathrm{w}=-1.0$. The pressure data indicated that no local pressure maximum can be observed on the suction side between the leading edge and $42 \% \mathrm{~S}_{\mathrm{m}}$. Tip leakage flow in this region is so weak that most of the scraping fluid makes its way through the gap, as was shown by Figure 11a. The pressure "drop" is therefore due to the inertia associated with the scraping fluid. Figure 11a shows how the scraping fluid decelerates before entering the gap from the suction side. This deceleration outside the gap near the suction side is believed to account for the pressure difference observed in Figure 12a.

At $S_{m}=63 \%$ the tip leakage jet is much stronger because the scraping ratio $\mathrm{R}$ has increased. The pressure drop between the pressure side and $y / w=0.35$ in Figure 12b indicates the acceleration of flow into the tip gap. The effect of the vena contracta on the casing pressure is further retarded (compare Figure 8), which may indicate stronger curvature of the streamlines at gap inlet. The pressure then recovers and rises towards the local pressure maximum, as the tip gap flow near the casing is slowed down due to the opposing scraping fluid (see Figure 11b). The extent of the pressure maximum, which indicates the lift off line, has increased dramatically and is now about a third of the overall pressure difference at the casing. The maximum has also moved away from the suction side, compared to $46 \% \mathrm{~S}_{\mathrm{m}}$. As the effect 
of scraping does not impinge on the suction side corner anymore, no area reduction for the tip leakage flow towards the gap exit was observed at this location. This is also confirmed in Figure 12b, where no decrease in $\mathrm{C}_{\mathrm{p}}{ }^{*}$ at gap exit is seen.

The extrapolation shown in Figure 12b suggests again that the local pressure maximum seems not to influence the driving suction side pressure. A simple model used to calculate the tip gap mass flow rate can therefore be based on the reduced static pressure difference between $90 \%$ span on the pressure side and the casing on the suction side.
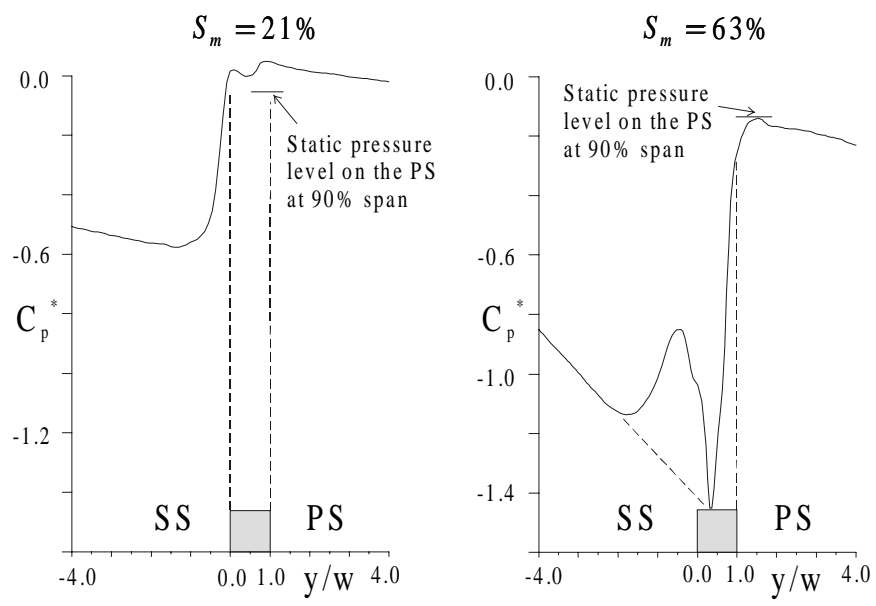

Figure 12: Comparison of $\mathrm{C}_{\mathrm{p}}^{*}$ between inducer and exducer

\section{Tip gap mass flow rate in a radial inflow turbine}

The mass flow rate over the blade tip was calculated along a constant $\mathrm{r} \theta$-value from the hot-wire measurements at four different chordwise positions. Assuming zero velocity at the blade tip surface the blade normal velocity in the relative frame was integrated over the height of the gap. The resulting mass flow rate per unit chord at $46 \%$ $\mathrm{S}_{\mathrm{m}}$ is presented in Figure 13 as an example. It needs to be remembered that the tip flow is being turned over the first quarter of the gap. In the region where the tip flow was more or less two-dimensional $(0<\mathrm{y} / \mathrm{w}$ $<0.75)$ the mass flow rate is almost constant and satisfies the requirement of the conservation of mass. In this region an average value was calculated. This value is reported in Figure 14 for each measured chordwise position. The average mass flow rate at $46 \% \mathrm{~S}_{\mathrm{m}}$ corresponds to $2 \%$ of the average blade passage mass flow rate per unit meridional chord.

The tip leakage mass flow model for axial turbines by Heyes and Hodson (1993) was applied to the present tip configuration, where an average discharge coefficient of 0.97 was chosen. The integrated mass flow rates in the exducer of the present radial turbine compare with those predicted by the axial turbine model, as indicated in Figure 14. This confirms the fact that the nature of tip leakage flow in the exducer of a radial turbine is similar to an axial turbine. But Figure 14 also shows that the same model overpredicts the amount of tip gap mass flow rate in the midsection by a factor of two and is even worse in the inducer. This is due to the effect of scraping as discussed above. It becomes apparent that a specific tip leakage mass flow model for radial turbines is needed.

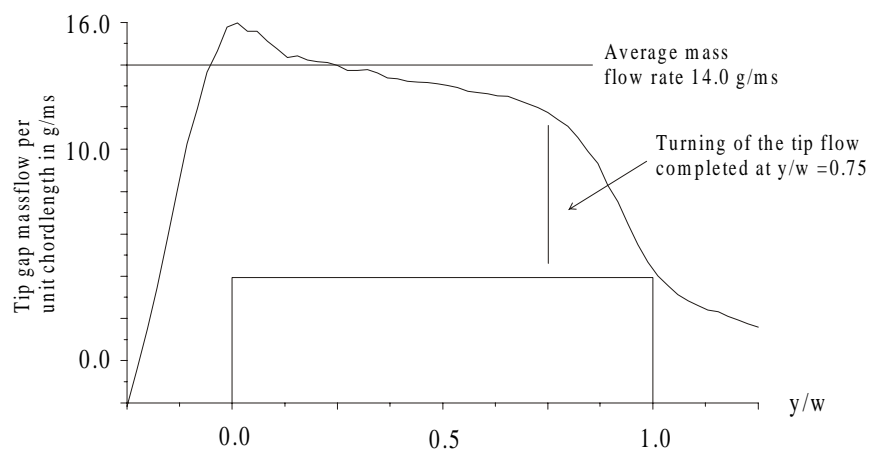

Figure 13: Mass flow rate per unit chord at $S_{m}=46 \%$

The most important observation that can be drawn from Figure 14 is that more mass flow passes through the tip gap near the exducer than near the inducer. This is partly due to the loading distribution (see Figure 9) but is also due to the effect of scraping. If high tip gap loss arises where there is high tip gap mass flow rate, this explains why radial clearance has a much larger effect on radial turbine stage efficiency than axial clearance.

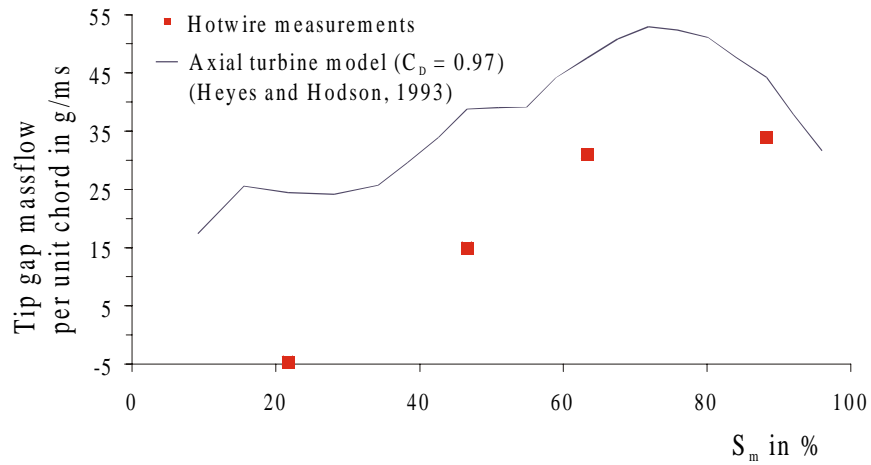

Figure 14: Tip gap mass flow rate along the meridional chord

\section{Tip gap loss in a radial inflow turbine}

Figure 15 indicates the normal kinetic energy at gap exit, calculated from the hot-wire measurements and defined as following

$$
Y=\frac{S_{\text {tip }} \cdot \int_{0}^{\tau} 0.5 \rho v_{n} v_{n}^{2} d z}{\dot{m}_{p} \cdot \Delta h_{0}}
$$

The loss coefficient $\mathrm{Y}$ represents the loss of efficiency that would occur, assuming that the kinetic energy transported by the normal gap velocity is ultimately lost (Yaras and Sjolander, 1992b). The kinetic energy of the scraping fluid was not taken into account. Figure 15 confirms that tip leakage loss in the exducer is more significant than in the inducer. In a radial turbine with a similar blade loading Futral and Holeski (1970) measured a 1.6 percent drop in stage efficiency for one percent increase in rotor exit clearance, but only a 0.15 percent drop in stage efficiency for one percent increase in clearance at the rotor inlet. The integrated loss coefficient between $60 \%$ and $100 \% \mathrm{~S}_{\mathrm{m}}$ (i.e. in the exducer) in Figure 15 is $\mathrm{Y}=1 \%$. This corresponds to a $1.7 \%$ loss of 
stage efficiency for a one percent clearance height and agrees very well with Futral and Holeski's result. The integrated loss over the whole chord in Figure 15 is $0.575 \%$ (for a $0.6 \%$ clearance height).

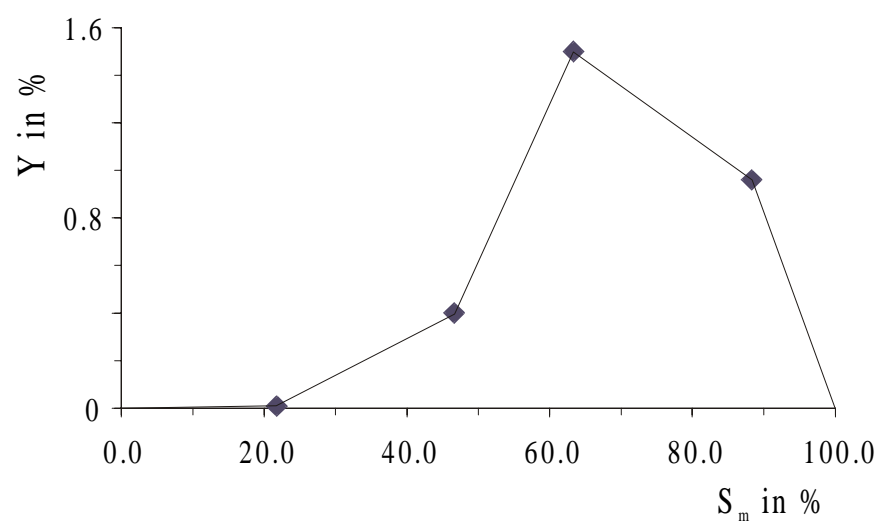

Figure 15: Tip gap loss coefficient for four different meridional positions

\section{CONCLUSIONS}

The details of tip clearance flow in radial turbines have been investigated for the first time. The nature of tip clearance flow in radial inflow turbines has been examined and understood. A detailed study at midchord was performed, which revealed that the tip clearance flow is opposed by scraping fluid in the relative frame. One part of this opposing scraping fluid was found to be dragged through the gap from the suction side to the pressure side. The remaining bulk of the scraping fluid was turned towards the hub and into the main flow direction. A dividing streamline separated the tip clearance flow and this second part of the scraping fluid. The dividing streamline causes a local pressure maximum outside the gap near the suction side, but does not effect the driving pressure difference.

The study of tip clearance flow in radial inflow turbines was extended over the whole chord. Blade speed and blade tip angle were found to play a key role for tip clearance effects in radial turbines. Tip clearance behaviour in a radial turbine was divided into three different regions.

In the inducer most of the scraping fluid forces its way through the tip gap and the tip gap mass flow rate over the first half of the chord is significantly reduced. This is one reason why a radial turbine suffers less from an increase in tip clearance than an axial turbine. At midchord little scraping fluid is dragged through the gap and from $60 \% \mathrm{~S}_{\mathrm{m}}$ towards the rotor exit the "dragging" effect of scraping finally disappears and the tip clearance flow in this region is dominated by pressure only.

The tip gap mass flow and the tip leakage loss for the present radial turbine were quantified. The results confirmed that radial clearance has a bigger effect on stage efficiency than axial clearance for the standard NASA design. The underlying physics of Futral and Holeski's experimental result (1970) seem to be the effect of high relative motion and low blade angle near the rotor inlet.

\section{ACKNOWLEDGEMENTS}

The authors wish to thank Ishikawajima-Harima Heavy Industries (IHI) Japan for their support of this project. The first author is thankful for being supported by the Swiss National Science Foundation (SATW) and for a grant from a foundation set up by ABB Switzerland. The authors would also like to thank Mr. C. Hall, formerly of the Whittle Laboratory, for his contribution to the project and for the help of the technicians Mr. J Saunders and Mr. B Taylor.

\section{REFERENCES}

Amedick, V, and Simon, H, 1997, "Numerical Simulation of the Flow through the Rotor of a Radial Inflow Turbine", ASME Paper 97GT-90.

Bindon, JP, 1987, "Pressure Distributions in the Tip Clearance Region of an Unshrouded Axial Turbine as affecting the Problem of Tip Burnout", ASME Paper 87-GT-230.

Futral, SM and Holeski, DE, 1970, "Experimental Results of varying the Blade-Shroud Clearance in a 6.02-inch Radial Inflow Turbine", NASA Technical Note D-5513.

Heyes, FJG, and Hodson, HP, 1993, "The Measurement and Prediction of the Tip Clearance Flow in Linear Turbine Cascades", Trans. of the ASME, Vol. 115, p. 376-382.

Huntsman, I, Hodson, HP, Hill, SH, 1991, "The Design and Testing of a Radial Flow Turbine for Aerodynamic Research", ASME 91-GT-220

Huntsman, I, and Hodson, HP, 1993, "A Laminar Flow Rotor for a Radial Inflow Turbine", AIAA-93-1796, AIAA/SAE/ASME/ASEE 29th Joint Propulsion Conference \& Exhibit

Huntsman, I, and Hodson, HP, 1994, "An Experimental Assessment of the Aerodynamic Performance of a Low-Speed Radial Inflow Turbine", AIAA-94-2932, AIAA/SAE/ASME/ASEE 30th Joint Propulsion Conference \& Exhibit

Pandya, A, and Lakshminarayana, B, 1983, "Investigation of the Tip Clearance Flow Inside and at the Exit of a Compressor Rotor Passage - Part I and II", Jnl. of Engineering for Power, Vol. 105, p. 117.

Rains D.A., 1954, "Tip Clearance Flows in Axial Flow Compressors and Pumps", Report No. 5, California Institute of Technology.

Sjolander, SA, and Cao, D, 1995, "Measurements of the Flow in an Idealised Turbine Tip Gap", Trans. of the ASME, Vol. 117, p. 578584.

Yaras MI, Sjolander SA, 1992, "Effects of Simulated Rotation on Tip Leakage in a Planar Cascade of Turbine Blades. Part I: Tip Gap Flow ",Trans. of the ASME, Vol. 114, p. 660-667.

Yaras, MI, and Sjolander, SA, 1992, "Prediction of Tip-Leakage Losses in Axial Turbines", Trans. of the ASME, Vol. 114, p. 204-210. 